\title{
Does 'Relationship Intelligence' Make Big Brains in Birds?
}

\author{
Isabella B.R. Scheiber", Brigitte M. Weiß, Katharina Hirschenhauser, Claudia A.F. Wascher, \\ Iulia T. Nedelcu and Kurt Kotrschal
}

\author{
Konrad Lorenz Forschungsstelle für Ethologie, A-4645 Grünau 11, Austria
}

\begin{abstract}
Lately, Emery et al. developed a bird-specific modification of the "social brain hypothesis", termed "relationship intelligence hypothesis". Although the idea may be valuable, we doubt that it is supported by sufficient evidence and critically discuss some of the arguments raised by the authors in favour of their new idea.
\end{abstract}

Recently, Emery et al. [1] proposed the "relationship intelligence hypothesis", essentially a bird-specific twist of the "social brain hypothesis" [2-5], suggesting that the equivalent of group complexity driving brain size in the polygynous mammals are the complexities of long-term dyadic partnerships in birds [1, but see 6]. We question, whether this interesting idea is sufficiently supported by evidence. In particular, we criticize the authors sweeping brain size comparisons over distant taxa and doubt their cause-effect interpretation that long-term pair bond would depend upon highly developed cooperative and cognitive skills [1]. Emery et al. [1] built their case on data from rooks (Corvus frugilegus) and jackdaws (C. monedula) and emphasize an important role of "some form of 'relationship intelligence" ", which social corvids and parrots possess, but small-brained birds like geese and albatrosses supposedly do not [1]. Three decades of data on life histories, social relationships and cognition in greylag geese (Anser anser) and parallel work in common ravens (C. corax) make us doubt such a "taxocentric" view of the birds' world [7-10]. We also disagree with their approach to deduce function from form, i.e. intelligence from brain size.

Individuals in social groups may form "valuable relationships" $[11,12]$, showing spatial proximity, behavioural synchrony, and social support. Primate-like features of relational complexity, however, are not only found in corvids, but also in the long-term affiliated greylag geese, which maintain extended associations between parents and offspring [7, 1315], and also between adult female siblings [16]. Social allies support each other actively (in agonistic interactions) and passively [stress-dampening effects, $7,13-15,17,18$ ] and thereby benefit in dominance rank and in access to resources [15]. Greylag geese may even understand third party relationships, because they show enhanced aggressiveness against individuals, which were recently involved in conflict with their social allies [7]. Although geese express their affiliations somewhat differently than primates or corvids, the level of coordination between partners is similar. Greylag partners coordinate their behaviour and physiology $[19,20]$ and goslings survive to fledging the more parents show finegrained cooperation among each other and with their offspring [19, 21, 22]. Clearly, not only "rooks display many of

*Address correspondence to this author at the Konrad Lorenz Forschungsstelle für Ethologie, Fischerau 11, 4645 Gruenau im Almtal, Austria;

E-mail:klf.gruenau@telecom.at the complex social traits so far only reported for hyenas, elephants, cetaceans, monkeys and apes" [1], but greylag geese do as well. This, of course, does not contradict the case of the "relationship intelligence hypothesis", but indicates that socio-cognitive skills are not a privilege of some evolutionary pinnacles, as Emery et al. seem to assume [1].

Parrots and passerines are known to excel in more complex cognitive tasks than most other bird species [23] and they possess relatively large telencephala [24, 25]. Despite the social complexity of greylag geese, their brains are smaller relative to those of corvids or parrots [24-26]. Emery et al. conclude that this difference must be due to more sophisticated relationships between partners in corvids and parrots as opposed to geese $[1,24]$. Although altricial life history by itself allows the development of relatively larger brains than precocial ontogeny [24-26], a within-clade comparison reveals that greylag geese are among the "brainiest" of the Anatidae [27]. Moreover, the largest reduction in brain size due to domestication is found in the goose hippocampus $[31 \%, 27]$, which is not only related to spatial performance [28], but also processes "transient social relationships, i.e. representing both past events and declarative knowledge" [1]. Social context may well drive brain size or structural adaptations in closely related species, but in comparing distantly related taxa, such effects are likely to be masked by evolutionary history.

In fact, avian sociality is not always related to big brains. By conventional and phylogenetic statistics, Iwaniuk and Arnold [29] found that most comparisons of cooperative breeding and brain size across 155 species of the passeriform parvorder Corvida (sensu [30]) yielded non-significant results. Along the same lines, not all species with large telencephala engage in complex social behaviour [24, 25]. Owls (Strigidae) and frogmouths (Podargidae), for example, are territorial, nocturnal perch hunters and share binocular vision and similar saccadic eye movements. Their large telencephala are due to an enlargement of the visual Wulst [25]. A1though social behaviour is largely unstudied in owls, it is unlikely to be as intense or as complex as the one observed in parrots, corvids or waterfowl. Therefore, Emery et al.'s core argument in favour of the "relationship intelligence hypothesis" [1], brain size, does not hold.

Furthermore, we dispute that the cognitive skills associated with cooperation are a crucial prerequisite for long-term pair bonding [1] and suggest the opposite: long-term pair bonding may be a key factor for the development of "coop- 
erative cognition". Long-term pair bonds are common in birds and are not restricted to "brainy" species. The core machinery for long-term pair bonding seems to be a common vertebrate socio-sexual brain [31] and bonding mechanisms [32]. Therefore, reproductive demands (i.e. monogamy and biparental care) and physiology glue pairs together. Elaborate cognition provides the topping rather than the matrix. Actually, the impressive cognitive skills of ravens, crows and jays revolve around food caching [8, 33-36], the context of which is less "relational" within dyads than competitive within groups. Furthermore, in corvids, geese, and many other birds, long-term monogamy is embedded in group settings of mammal-like complexity, which casts doubts on the assumption that bird monogamy per se sets a fundamentally different stage for the evolution of altered cognitive skills than does polygyny in mammals [5].

Finally, we disagree with the idea that cooperation requires fundamentally different cognitive abilities than competition [1]. Functionally, competition and cooperation are two different manifestations of social intelligence, but in both cases, individuals need appropriate "episodic memory" to keep track of past interactions as a base for future decisions $[37,38]$. The main difference between cooperation and competition may be how these cognitive skills are applied in particular dyadic interactions. Cooperative abilities may even form the base for advanced competitive abilities, i.e. when several animals cooperate to out-compete others. Chimpanzee intelligence, for example, seemed to be mainly competitive $[39,40]$, but in appropriate contexts chimpanzees are capable of "altruistic cooperation" [41].

To conclude, there is an obvious need for a wider view and proper phylogenetic approach [42] when discussing brain size and social intelligence in birds. We consider the "relationship intelligence hypothesis" as a potentially valuable extension of the "social brain hypothesis", but doubt whether it is presently supported by adequate evidence.

\section{ACKNOWLEDGEMENTS}

We are grateful to four anonymous reviewers for their constructive criticism. We acknowledge funding by the FWF (P18601-B17; 18744-B03; P15766-B03), the 'Verein der Förderer der Konrad Lorenz Forschungsstelle', and the Cumberland Wildpark, Grünau.

\section{REFERENCES}

[1] Emery NJ, Seed AM, von Bayern P, Clayton NS.. Cognitive adaptations of social bonding in birds. Philos T R Soc B 2007; 362: 489-505.

[2] Dunbar RIM.. The social brain hypothesis. Evol Anthropol 1998; 6: $178-90$

[3] Byrne RW., Whiten A.. Machiavellian intelligence: Social expertise, and the evolution of intellect in monkeys, apes, and humans. Oxford, UK: Clarendon Press; 1988.

[4] Humphrey NK.. In: Bateson P, Hinde R, Eds. Growing Points in Ethology, Cambridge, University Press 1976; 303-21.

[5] Jolly A.. Lemurs social behavior and primate intelligence. Science 1966; 153: 501-7.

[6] S. D. Healy, C. Rowe. A critique of comparative studies of brain size. P. Roy Soc B - Biol Sci 2007; 274: 453-64.

[7] Weiß BM, Frigerio D, Hemetsberger J, Kotrschal K, Scheiber IBR.. In: Ramirez RN. , Ed. Family Relations: Issues and Challenges, New York, Nova Science Publishers 2008.

[8] T. Bugnyar, B. Heinrich. Pilfering ravens, Corvus corax, adjust their behaviour to social context and identity of competitors. Anim Cog 2006; 9: 369-76.
[9] Fritz J, Bisenberger A, Kotrschal K. Stimulus enhancement in greylag geese: Socially mediated learning of an operant task. Anim Behav 2000a; 59: 1119-25.

[10] Hemetsberger J. In: Kotrschal K, Müller G, Winkler H, Eds. Konrad Lorenz und seine verhaltensbiologischen Konzepte aus heutiger Sicht, Fürth, Filander Verlag 2001; 249-60.

[11] Kummer H. On the value of social relationships to nonhuman primates: A heuristic scheme. Soc Sci Inform 1978; 17: 687-705.

[12] van Schaik CP, Aureli F. In: Aureli F, De Waal FBM., Eds. Natural Conflict Resolution, Berkeley, University of California Press 2000; 307-33.

[13] Frigerio D, Weiß BM, Dittami J, Kotrschal K. Social allies modulate corticosterone excretion and increase success in agonistic interactions in juvenile hand-raised Greylag Geese (Anser anser). Can J Zool 2003; 81: 1746-54.

[14] Scheiber IBR, Weiß BM, Frigerio D, Kotrschal K. Active and passive social support in families of Greylag Geese (Anser anser). Behaviour 2005; 142: 1535-57.

[15] Weiß BM, Kotrschal K. Effects of passive social support in juvenile Greylag Geese (Anser anser): A study from fledging to adulthood. Ethology 2004; 110: 429-44.

[16] Frigerio D, Weiß BM, Kotrschal K. Spatial proximity among adult siblings in Greylag Geese (Anser anser): Evidence for female bonding? Acta Ethol 2001; 3: 121-5.

[17] Kotrschal K, Hemetsberger J, Weiß BM. In: Vasey P, Sommer V, Eds. Homosexual Behaviour in Animals: An Evolutionary Perspective, Cambridge, UK, Cambridge University Press 2006; 45-76.

[18] Kotrschal K, Hirschenhauser K. Möstl E. The relationship between social stress and dominance is seasonal in Greylag Geese. Anim Behav 1998; 55: 171-6.

[19] Hirschenhauser K, Möstl E, Kotrschal K.. Withinpair testosterone covariation and reproductive output in Greylag Geese (Anser anser). Ibis 1999 b; 141: 577-86.

[20] Weiß BM, Möstl E, Hirschenhauser K. Within-pair testosterone compatibility as a currency for pairbond quality in greylag geese? Horm Behav 2005; 48: 133.

[21] Scheiber IBR, Wascher CAF, Kotrschal K. Biparental care in Greylag geese: Heart rate as a measure of parental contribution. J Ornithol 2006; 147: 245-6.

[22] Schneider JM, Lamprecht. J. The importance of biparental care in a precocial, monogamous bird, the Bar-headed Goose (Anser indicus). Behav Ecol Sociobiol 1990; 27: 415-9.

[23] Emery NJ, Clayton NS.. The mentality of crows: Convergent evolution of intelligence in corvids and apes. Science 2004; 306: 19037.

[24] Burish MJ, Kueh HY, Wang SS-H. Brain architecture and social complexity in modern und ancient birds. Brain Behav Evol 2004; 63: 107-24.

[25] Iwaniuk AN, Hurd PL. The evolution of cerebrotypes in birds. Brain Behav Evol 2005; 65: 215-30.

[26] Iwaniuk AN, Nelson JE.. Developmental differences are correlated with relative brain size in birds: A comparative analysis. Can J Zool 2003 a; 81: 1913-28.

[27] Ebinger P, Löhmer R. A volumetric comparison of brains between greylag geese (Anser anser L.) and domestic geese. J Brain Res 1987; 28: 291-9.

[28] Macphail E. M.. In: Roth G, Wullimann MF, Eds. Brain Evolution and Cognition, New York, NY, John Wiley \& Sons, Inc. 2001; 401-30.

[29] Iwaniuk AN, Arnold KE.. Is cooperative breeding associated with bigger brains? A comparative test in the Corvida (Passeriformes). Ethology 2004; 110: 203-20.

[30] Sibley CG, Ahlquist JE. Phylogeny and Classification of the Birds: A Study in Molecular Evolution. New Haven, CT: Yale University Press; 1990.

[31] Goodson JL.. The vertebrate social behavior network: Evolutionary themes and variations. Horm Behav 2005; 48: 11-22.

[32] Curley JP, Keverne EB. Genes, brains and mammalian social bonds. Trends Ecol Evol 2005; 20: 561-7.

[33] Dally J, Emery NJ, Clayton NS. Food-caching Western scrub jays keep track of who was watching when. Science 2006; 312: 1662-5.

[34] Bugnyar T, Kotrschal K. Observational learning and the raiding of food caches, Corvus corax: Is it 'tactical' deception? Anim Behav 2002a; 64: 185-95. 
[35] Bugnyar T. Heinrich B. Ravens, Corvus corax, differentiate between knowledgeable and ignorant competitors. P Roy Soc B Biol. Sci 2005a; 272: 1641-6.

[36] Bugnyar T, Stöwe M. Heinrich B. The ontogeny of caching in ravens. Anim Behav 2007; 74: 757-67.

[37] Clayton NS, Griffiths DP, Emery N J, Dickinson A. Elements of episodic-like memory in animals. Philos T R Soc B 2001; 356: 1483-91.

[38] Clayton NS, Dickinson A. Episodic-like memory during cache recovery by scrub jays. Nature $1998 ; 395: 272-4$.
[39] Hare B, Tomasello M. Chimpanzees are more skilful in competitive than cooperative cognitive tasks. Anim Behav 2004; 68: 57181 .

[40] Hare B. Can competitive paradigms increase the validity of experiments on primate social cognition? Anim Cog. 2001; 4: 269-80.

[41] Warneken F, Hare B, Melis AP, Hanus D, Tomasello M. Spontaneous altruism by chimpanzees and young children. PLoS 2007; 5 : e184.

[42] Felsenstein J. Phylogenies and the comparative method. Am Nat 1985; 125: 1-15. 